\title{
Osteoporotik Hastalarda Uyku Kalitesinin Yaşam Kalitesine Etkisi
}

\author{
Effects of Sleep Quality on Quality of Life in Patients with Osteoporosis \\ Şule Şahin Onat, Sibel Ünsal Delialioğlu, Seda Biçer, Sumru Özel \\ Ankara Fizik Tedavi Eğitim ve Araştırma Hastanesi, Ankara, Türkiye
}

\section{Özet}

Amaç: Bu çalışmanın amacı osteoporotik bireylerde uyku kalitesinin değerlendirilmesi, uyku kalitesi ile ilişkili olabilecek faktörlerin belirlenmesi ve uyku kalitesi ile yaşam kalitesi arasındaki ilişkinin araştırıımasıdır.

Gereç ve Yöntem: Çalışmaya polikliniğimize başvuran 154 osteoporoz tanısı konulmuş hasta alındı. Hastalara yaş, cinsiyet, medeni durum, eğitim düzeyi, meslek, boy, kilo, alkol kullanımı, sigara kullanımı, fiziksel aktivite düzeyi, süt tüketimi, geçirilmiş frajilite kırığı öyküsünü içeren sorgulama formu dolduruldu. Kemik mineral yoğunluğu ölçümü DEXA ile lomber bölge ve femur boynundan yapıldı. Olguların torakal ve lomber vertebra grafileri çekilerek kompresyon kırıkları olup olmadığı kaydedildi. Sırt ağıısını değerlendirmek için Görsel Analog Skala (GAS) kullanıldı. Hastaların uyku kalitesini değerlendirmek için Pittsburg Uyku Kalitesi Indeksi (PUKi), yaşam kalitesini değerlendirmek için Avrupa Osteoporoz Kurumu Yaşam Kalitesi Anketi (QUALEFFO) kullanıldı.

Bulgular: Çalışmaya alınan 154 hastanın 65'inde $(\% 42,2)$ uyku bozukluğu varken 89'unda $(\% 57,8)$ uyku bozukluğu bulunmamaktaydı. Uyku bozukluğu olan osteoporoz hastalarında yaş ortalaması, kadın cinsiyet, evli olmama, aktif çalışmama, okuryazar olmama durumu uyku bozukluğu olmayanlardan yüksek, haftalık süt tüketim ortalaması daha düşük bulundu. Vertebral kompresyon kırı̆ı uyku bozukluğu olan osteoporoz hastalarında uyku bozukluğu olmayanlardan daha fazlaydı. Hem lomber hem de femur T ve Z değerleri, GAS değerleri uyku bozukluğu olan osteoporoz hastalarında uyku bozukluğu olmayanlardan istatistiksel olarak daha yüksekti $(p<0,05)$. QUALEFFO yaşam kalitesi ölçeğinin tüm alt parametreleri ve toplam değeri uyku bozukluğu olan osteoporoz hastalarında uyku bozukluğu olmayanlardan istatistiksel olarak anlamlı şekilde daha yüksekti $(p<0,05)$. PUKI skoruyla QUALEFFO yaşam kalitesi ölçeğinin alt parametre skorlarından ağıı arasında orta derece güçte; fiziksel işlev, sosyal işlev, genel sağlık algılaması ve toplam skor arasında zayıf güçte pozitif anlamlı korelasyon bulundu.

Sonuç: Osteoporozlu hastalarda gözlenen uyku bozuklukları yaş, cinsiyet, medeni durum, eğitim seviyesi, diyet gibi faktörlerle ilintilidir. Uyku bozuklukları osteoporotik hastaların yaşam kalitesinin daha da düşmesine neden olmaktadır. (Türk Osteoporoz Dergisi 2013;19: 32-7)

Anahtar kelimeler: Osteoporoz, uyku bozukluğu, yaşam kalitesi

\section{Summary}

Aim: The purpose of the study was to evaluate sleep quality in osteoporotic individuals, and to determine the associated factors with sleep quality and to investigate the relationship between quality of life and sleep quality

Material and Methods: 154 patients with osteoporosis admitted to our outpatient clinic included in the study. A questionnaire that was including patients age, sex, marital status, education level, occupation, height, weight, alcohol use, smoking, physical activity level, milk consumption and previous fragility fracture was completed. DXA was used to determine bone mineral density of the lumbar spine and femoral neck. Thoracal and lumbar compression fractures were evaulated with thoracal and lumbar radiography. Visual analog scale was used to evaluate back pain. Pittsburgh sleep quality index was used to determine sleep quality and QUALEFFO was used to evaluate quality of life in the individuals. Results: A total of 154 individuals included in the study. 65 patients (42.2\%) had a sleep disorder and 89 patients (57.8\%) hadn't a sleep disorder. Mean age, female gender, not being married, not working actively, illiteracy rates were higher; the mean of weekly consumption of milk were lower in patients with sleep disorders than without sleep disorders. Vertebral compression fracture was more in patients with sleep disorders than without sleep disorders. Both lumbar and femoral T and Z values, VAS values were significantly higher in patients with sleep disorders than without sleep disorders $(p<0.05)$. The value of all sub-parameters of quality of life scale QUALEFFO and total value were significantly higher in patients with sleep disorders than without sleep disorders $(p<0.05)$.

Conclusion: Sleep disorders in patients with osteoporosis are releated to factors such as age, sex, marital status, education level and diet. Sleep disorders cause a further decrease in the quality of life of patients with osteoporosis. (Turkish Journal of Osteoporosis 2013;19: 32-7) Key words: Osteoporosis, sleep disorders, quality of life 


\section{Giriş}

Uyku 24 saatlik sirkadyen endojen ritim içinde kişinin duysal veya diğer bir stimulusla uyarılıp uyandırılabileceği geçici bir bilinçsizlik dönemidir (1). Uyku, organizmanın dinlenmesini sağlayan bir hareketsizlik hali olmasının yanında, tüm vücudu yaşama yeniden hazırlayan bir yenilenme dönemi olup, bireylerin yaşam kalitesini ve sağlığını etkileyen temel günlük yaşam aktivitelerinden biridir. Bazı hastalıklar hem fiziksel hem de psikolojik stres oluşturarak uyku düzenini etkileyebilmektedir. Uyku problemlerine yol açabilen durumlardan biri de osteoporozdur. Osteoporoz ağrıya neden olarak, fiziksel rahatsızlıklar yaratarak, anksiyete ve depresyon gibi problemlere yol açarak uyku problemlerine neden olabilir. Literatüre baktığımızda birçok hastalıkta uyku bozuklukları araştırılmış olmakla birlikte, osteoporozda uyku kalitesi ve uyku kalitesinin yaşam kalitesine etkisi ile ilgili veriler bulunmamaktadır. $\mathrm{Bu}$ çalışmanın amacı osteoporotik bireylerde uyku kalitesinin değerlendirilmesi, uyku kalitesi ile ilişkili olabilecek faktörlerin belirlenmesi ve uyku kalitesi ile yaşam kalitesi arasındaki ilişkinin araştırılmasıdır.

\section{Gereç ve Yöntem}

Çalışmaya polikliniğimize başvuran Dünya Sağlık Örgütü (DSÖ) kriterlerine göre dual enerji X-ray absorpbsiyometre (DXA) (Lunar DPX-IQ) ile osteoporoz (OP) tanısı konmuş 154 hasta başvuruya göre ardı sıra şeklinde alındı. Hastane lokal etik kurulundan onay alındı. Hastalar çalışma ile ilgili bilgilendirilerek hasta onamları alındı.

Hastalara yaş, cinsiyet, medeni durum (evli\evli değil), eğitim düzeyi (okuryazar\okuryazar değil), meslek (aktif çalışan\aktif çalışmayan), boy, kilo, vücut kitle indexi $\left((\text { kilo/(boy })^{2}\right)$, alkol kullanımı (içmiyor\sosyal içici\sürekli içici), sigara kullanımı (paket\gün\yıl), fiziksel aktivite düzeyi (düzenli egzersiz yapıyor \ara sıra egzersiz yapıyor \hiç egzersiz yapmıyor), süt tüketimi (bardak\hafta), geçirilmiş frajilite kırığı öyküsünü içeren sorgulama formu dolduruldu.

Kemik mineral yoğunluğu (KMY) ölçümü dual enerji x-ray absorpbsiyometre (DXA) ile lomber bölge ve femur boynundan yapıldı. DSÖ kriterlerine göre T skoru -2,5 ve üzeri olan hastalar çalışmaya dahil edildi. Olguların torakal ve lomber vertebra grafileri çekilerek kompresyon kırıkları olup olmadığı belirlendi. Tüm hastalarda sırt ağrısını değerlendirmek için Görsel Analog Skala (GAS) kullanıldı. Akut kompresyon kırığı olan hastalar çalışmaya alınmadı.

Hastaların uyku kalitesini değerlendirmek için Pittsburg Uyku Kalitesi İndeksi (PUKi) kullanıldı. Buysse ve ark.ları tarafından geliştirilen PUKI, son bir ay süresindeki uyku kalitesini değerlendirmek amacıyla toplam 19 sorudan ve 7 bileşenden oluşmaktadır (2). Puanlamaya 18 madde ve 7 bileşen katılır. Her bir madde 0-3 puan üzerinden değerlendirilmektedir ve 7 bileşen puanının toplamı, toplam PUKi puanını oluşturur. Toplam puan 0-21 arasında bir değere sahiptir, toplam puanın yüksek oluşu uyku kalitesinin kötü olduğunu göstermektedir. Toplam PUKi puanın $\leq 5$ olması "iyi uyku kalitesi"ni, >5 olması ise "kötü uyku kalitesi"ni göstermektedir (2). Indeksin, geçerliği ve güvenirliği Ağargün ve ark.ları tarafından yapılmıştır ve Türk toplumuna uygun olduğu belirlenmiştir (3). Testin tanısal duyarlılığı \%89,6, özgüllüğü \%86,5'tir. (3).

Yaşam kalitesini değerlendirmek için Avrupa Osteoporoz Kurumu Yaşam Kalitesi Anketi (QUALEFFO) kullanıldı. Avrupa Osteoporoz Kurumu Yaşam Kalitesi Anketi (QUALEFFO-41) osteoporozda yaşam kalitesi değerlendirilmesinde yaygın olarak kullanılan ve pek çok ülkede geçerlilik çalışmaları yapılmış, tekrarlanabilir, hastalarla kontrol grubu arasındaki farklılıkları açıkça ortaya koyabilen bir ölçektir (4). Lips ve ark.ları tarafından yapılan bir geçerlilik çalışmasında yeniden test edilme özelliğinin ve iç tutarlığının iyi olduğu saptanmış, vertebra kırığı olan hastalar ve kontroller arasındaki farkı ayırt edebildiği gösterilmiştir (4). QUALEFFO'nun Türkçe versiyonu Koçyiğit ve ark.ları tarafından hazırlanmış testin güvenilirlik ve geçerlilik çalışması yapılmıştır (5). QUALEFFO-41, ağrı (5 madde), fiziksel fonksiyon (17 madde), sosyal etkinlik (7 madde), genel sağlık değerlendirmesi (3 madde) ve zihinsel fonksiyon (9 madde) gibi; sağlığın beş boyutunu inceleyen 5 alt ölçekten oluşur. (4). QUALEFFO-41 ölçeğindeki soruların yanıtları seçenek sırasıyla 1'den (sağlıklı) 5'e (sağlıksız) kadar puanlanmaktadır. 33, 34, 35, 37, 39 ve 40. sorular puanlanırken, seçeneklerin sırası ters çevrilerek sıralamanın diğer sorularda olduğu gibi en iyi sağlık durumundan (1 puan), en kötü sağlık durumuna (5 puan) doğru olması sağlanmaktadır. Üç seçenekli sorular $(23,24,25,26)$ için birinci soruya 1, ikinci soruya 3 , üçüncü soruya 5 puan verilmektedir. Dört seçenekli sorular $(27,28,29)$ için birinci soruya 1, ikinci soruya 2,3, üçüncü soruya 3,6 ve dördüncü soruya 5 puan verilmiştir. 24, 26 ve 29.sorular için "bu soru benim için geçerli değil" ya da "sinema ya da tiyatroya gitmiyorum" seçenekleri için puan verilmemiş̧ir (6). Bölüm puanı ve toplam puan, puanların 100 üzerinden yapılan bir ölçüme aktarılmasıyla hesaplanmaktadır. Ölçekteki her bir alt grup ve toplam sonuç için, 0 puan en iyi sağlık durumunu gösterirken, 100 puan en kötü sağlık durumunu göstermektedir (4).

\section{İstatistiksel Analiz}

İstatistiksel analizlerde SPSS (Statistical Package for Social Sciences) 15,0 istatistik paket programı kullanıldı. $p<0,05$ değeri anlamlı kabul edildi. Tanımlayıcı istatistikler ortalama \pm standart sapma olarak gösterildi. Uyku bozukluğu olan ve olmayan osteoporotik hastalar arasında kategorik verilerin karşılaştırılmasında ki-kare testi, gruplar arasında ortalamalar yönünden farkın önemliliği Student's t testi ile değerlendirildi. PUKi skoruyla QUALEFFO yaşam kalitesi ölçeğinin alt parametre skorları arasındaki ilişki Pearson korelasyon analizi ile incelendi.

\section{Bulgular}

Çalışmaya alınan toplam 154 bireyin 114'ü kadın (\%74), 40'। (\%26) erkekti. Hastaların yaş ortalaması 73,96 $\pm 6,43$ yıldı. Hastaların 65'de $(\% 42,2)$ uyku bozukluğu varken 89'unda $(\% 57,8)$ uyku bozukluğu bulunmamaktaydı. Uyku bozukluğu olan osteoporoz hastalarının yaş ortalaması $(76,55 \pm 6,39)$ uyku 
bozukluğu olmayan osteoporoz hastalarının yaş ortalamasından $(72,06 \pm 5,80)$ istatistiksel olarak anlamlı şekilde yüksekti $(p=0,0001)$. Hastaların demografik ve klinik özellikleri ilgili tabloda özetlenmiştir (Tablo 1). Buna göre uyku bozukluğu olan osteoporoz hastalarında kadın cinsiyet, evli olmama, aktif çalışmama, okuryazar olmama durumunun uyku bozukluğu olmayan osteoporoz hastalarından istatistiksel olarak anlamlı şekilde yüksek olduğu görülmektedir $(p<0,05)$. İki grup arasında ise alkol kullanımı, sigara kullanımı ve fiziksel aktivite düzeyi açısından farklılık yoktu ( $p>0,05)$.

Uyku bozukluğu olanların VKi ortalamasıly $(29,55 \pm 4,36)$ uyku bozukluğu olmayanların VKi ortalaması $(28,92 \pm 3,92)$ arasında istatistiksel olarak anlamlı farklılık saptanmadı $(p=0,348)$.

Haftalık süt tüketim ortalaması uyku bozukluğu olan osteoporoz hastalarında $(8,46 \pm 3,77$ bardak) uyku bozukluğu olmayanlarınkinden $(10,47 \pm 4,26$ bardak) istatistiksel olarak anlamlı şekilde düşük bulundu $(p=0,003)$. PUKi skorlarının ise diyette yetersiz kalsiyum alan osteoporoz hastalarında $(7,83 \pm 5,78)$ yeterli kalsiyum alanlardan $(5,36 \pm 4,46)$ istatistiksel olarak anlamlı şekilde yüksek olduğu saptandı $(p=0,002)$.
Vertebral kompresyon kırığı uyku bozukluğu olan osteoporoz hastalarının 28'inde $(\% 43,1)$, uyku bozukluğu olmayan osteoporoz hastalarının 4'ünde $(\% 4,5)$ bulunmaktaydı. Bu fark istatistiksel olarak anlamlıydı $(p=0,0001)$. Nonvertebral kırık uyku bozukluğu olan osteoporoz hastalarının 2'sinde $(\% 3,1)$, uyku bozukluğu olmayan osteoporoz hastalarının 2'sinde $(\% 2,2)$ bulunmaktaydı. Bu fark istatistiksel olarak anlamlı değildi $(p=0,749)$.

Kemik mineral yoğunluğu, GAS değerleri ve QUALEFFO yaşam kalitesi ölçeği skor ortalamalarının karşılaştırılması ilgili tabloda gösterilmiştir (Tablo 2). Lomber ve Femur $\mathrm{T}$ ve $\mathbf{Z}$ değerlerinin uyku bozukluğu olan osteoporoz hastalarında uyku bozukluğu olmayanlardan istatistiksel olarak daha yüksek olduğu görülmektedir $(p<0,05)$. Sırt ağrısının değerlendirildiği GAS değerlerinin uyku bozukluğu olan osteoporoz hastalarında uyku bozukluğu olmayanlardan daha yüksek olduğu bulundu $(p<0,05)$. QUALEFFO yaşam kalitesi ölçeğinin ağrı, fiziksel işlev, sosyal işlev, genel sağlık algılamasından oluşan tüm alt parametrelerinin ve toplam değerinin uyku bozukluğu olan osteoporoz hastalarında uyku bozukluğu olmayanlardan

\section{Tablo 1. Uyku bozukluğu olan ve olmayan osteoporoz olgularının özellikleri}

\begin{tabular}{|c|c|c|c|}
\hline & $\begin{array}{c}\text { Uyku bozukluğu olan } \\
\mathrm{n}(\%)\end{array}$ & $\begin{array}{c}\text { Uyku bozukluğu olmayan } \\
n(\%)\end{array}$ & $\mathrm{p}$ \\
\hline \multicolumn{4}{|l|}{ Cinsiyet } \\
\hline Kadın & $55(84,6)$ & $59(66,3)$ & \multirow{2}{*}{$0,010^{*}$} \\
\hline Erkek & $10(15,4)$ & $30(33,7)$ & \\
\hline \multicolumn{4}{|l|}{ Medeni durum } \\
\hline Evli & $37(56,9)$ & $68(76,4)$ & \multirow{2}{*}{$0,010^{*}$} \\
\hline Evli değil & $28(43,1)$ & $21(23,6)$ & \\
\hline \multicolumn{4}{|l|}{ Meslek } \\
\hline Aktif çalışmayan & $65(100)$ & $79(88,8)$ & \multirow[t]{2}{*}{$0,005^{\star}$} \\
\hline Aktif çalışan & $0(0)$ & $10(11,2)$ & \\
\hline \multicolumn{4}{|l|}{ Eğitim durumu } \\
\hline Okuryazar & $26(40)$ & $50(56,2)$ & \multirow[t]{2}{*}{$0,047^{\star}$} \\
\hline Okuryazar değil & $39(60)$ & $39(43,8)$ & \\
\hline \multicolumn{4}{|l|}{ Alkol kullanımı } \\
\hline İçmiyor & $61(93,8)$ & $84(94,4)$ & \multirow{3}{*}{0,628} \\
\hline Sosyal içici & $4(6,2)$ & $4(4,5)$ & \\
\hline Sürekli içici & 0 & $1(1,1)$ & \\
\hline \multicolumn{4}{|l|}{ Sigara kullanımı } \\
\hline Var & $9(13,8)$ & $15(16,9)$ & \multirow{2}{*}{0,611} \\
\hline Yok & $56(86,2)$ & $74(83,1)$ & \\
\hline \multicolumn{4}{|l|}{ Fiziksel aktivite düzeyi } \\
\hline Düzenli egzersiz yapan & $2(3,1)$ & $8(9)$ & \multirow{3}{*}{0,129} \\
\hline Arasıra egzersiz yapan & $20(30,8)$ & $36(40,4)$ & \\
\hline Hiç egzersiz yapmayan & $42(64,6)$ & $45(50,6)$ & \\
\hline
\end{tabular}


Tablo 2. Uyku bozukluğu olan ve olmayan osteoporoz olgularının risk faktörleri, KMY, VAS değerleri ve QUALEFFO yașam kalitesi ölçeği skor ortalamalarının karșilaștırılması

\begin{tabular}{|c|c|c|c|}
\multicolumn{2}{|c|}{$\begin{array}{c}\text { Uyku bozukluğu olan OP } \\
\text { hastaları }\end{array}$} & $\begin{array}{c}\text { Uyku bozukluğu olmayan OP } \\
\text { hastaları }\end{array}$ \\
\hline Majör risk faktörü ortalaması & $2,10 \pm 1,87$ & $1,37 \pm 0,78$ & $0,0001^{*}$ \\
\hline Minör risk faktörü ortalaması & $1,13 \pm 0,68$ & $0,94 \pm 0,74$ & 0,099 \\
\hline Lomber T değeri & $3,51 \pm 0,72$ & $3,14 \pm 0,54$ & $0,0001^{*}$ \\
\hline Lomber Z değeri & $1,63 \pm 0,67$ & $1,26 \pm 0,51$ & $0,0001^{*}$ \\
\hline Femur T değeri & $2,69 \pm 0,70$ & $2,34 \pm 0,62$ & $0,002^{*}$ \\
\hline Femur Z değeri & $1,07 \pm 0,59$ & $0,79 \pm 0,38$ & $0,0001^{*}$ \\
\hline Sırt ağrısı GAS & $6,90 \pm 2,14$ & $4,58 \pm 1,66$ & $0,0001^{*}$ \\
\hline QUALEFFO & & & $0,0001^{*}$ \\
\hline Ağrı & $56,93 \pm 25,09$ & $30,33 \pm 16,98$ & $0,0001^{*}$ \\
\hline Fiziksel Işlev & $39,38 \pm 1,57$ & $25,38 \pm 15,13$ & $0,0001^{*}$ \\
\hline Sosyal Iş̧lev & $53,35 \pm 12,13$ & $41,65 \pm 13,29$ & $0,0001^{*}$ \\
\hline Genel Sağlk Algılaması & $67,17 \pm 17,79$ & $54,38 \pm 9,56$ & $0,0001^{*}$ \\
\hline Ruh Hali & $54,58 \pm 14,54$ & $63,07 \pm 8,95$ & $0,0001^{*}$ \\
\hline Total Skor & $49,87 \pm 10,53$ & $39,21 \pm 7,59$ & \\
\hline
\end{tabular}

Tablo 3. PUKI skorunun QUALEFFO yașam kalitesi ölçeğinin alt parametre skorlarıla ilișkisi

\begin{tabular}{|l|l|l|}
\hline & PUKi $\mathbf{r}$ & PUKi $\mathbf{p}$ \\
\hline Ağrı & 0,577 & $0,0001^{*}$ \\
\hline Fi & 0,460 & $0,0001^{*}$ \\
\hline Si & 0,385 & $0,0001^{*}$ \\
\hline GSA & 0,461 & $0,0001^{*}$ \\
\hline RH & 0,460 & 0,0001 * \\
\hline Total & 0,544 & $0,0001^{*}$ \\
\hline
\end{tabular}

Fi: Fiziksel işlev, Si:Sosyal işlev, GSA:Genel sağlık algılaması RH:Ruh hali

istatistiksel olarak anlamlı şekilde daha yüksek olduğu bulundu $(p<0,05)$ (Tablo 3).

PUKi skoruyla QUALEFFO yaşam kalitesi ölçeğinin alt parametre skorlarından ağrı arasında orta derece güçte; fiziksel işlev, sosyal işlev, genel sağlık algılaması ve toplam skor arasında zayıf güçte pozitif anlamlı korelasyon bulundu (Tablo 3).

\section{Tartışma}

Uyku ömrümüzün üçte birini geçirdiğimiz, gizemleri henüz çözülememiş bir süreçtir. Uyku sürecinde yaşanan aksaklıklar bireyin genel sağlık durumunu ve günlük yaşam aktivitelerini doğrudan etkilemektedir (7).

Ilerleyen yaşla birlikte hem uyku ölçekleriyle hem de polisomnografiyle uyku kalitesini inceleyen çalışmalarda uyku kalitesinin bozulduğu ve uyku miktarının yeterli olmadığı gösterilmiştir $(7,8)$. Chui ve ark.ları çalışmalarında yaşlıların \%75'inin uyku bozukluğundan yakındığını ifade etmektedir (9). Bizim de çalışmamızda uyku bozukluğu olan osteoporoz hastalarının yaş ortalamasının uyku bozukluğu olmayanlardan yüksek olması ilerleyen yaşla birlikte uyku bozukluklarının artmasından kaynaklanmaktadır.

Yapılan çalışmalar kadınların erkeklere göre daha fazla uyku sorunu yaşadıklarını göstermektedir (10). Fakat erkeklerin kadınlara göre daha çok uyku problemi yaşadıklarını gösteren çalışmalar da bulunmaktadır $(11,12)$. Çalışmamızda da uyku bozukluğu olan osteoporoz hastalarında kadın cinsiyetin daha fazla bulunması örnekleme alınan hastaların büyük kısmının kadınlardan oluşmasından kaynaklanabilir.

Uyku gereksiniminin evrensel olmasına bağlı olarak medeni durumun uyku kalitesini etkilememesi beklenmektedir. Çalışmamızda uyku bozukluğunun evli olmayanlarda daha fazla olması düşündürücüdür. Bu durum kadınlarda boşanma ya da eşin kaybedilmesine bağlı yaşadıkları anksiyete, mevcut ekonomik ve sosyal belirsizliklerden kaynaklanabilir.

Çalışmamızda osteoporotik hastaların eğitim seviyesi düştükçe uyku kalitelerinin de düştüğü gözlenmektedir. Birçok araştırmacı da eğitim düzeyi daha iyi olan bireylerin fiziksel ve mental sağlıklarının ve buna bağlı olarak da uyku kalitelerinin daha iyi olduğunu göstermiştir $(11,13)$

Az veya orta miktarda alkol alınması başlangıçta uyku verici etki yapıp, uykuya dalmayı kolaylaştırırken zamanla uykunun bölünmesine, uyku evreleri arasındaki geçişlerin artmasına ve REM uyku sunda azalmaya neden olmaktadır. Ohayon ve ark. ları da uyku sorunlarına neden olan risk faktörleri arasında alkolün yer aldığını ifade etmiştir (14). Yapılan araştırmalarda sigaranın da uyku bozukluklarının gelişmesinde önemli bir risk faktör olduğu ve sigara içenlerin uyku kalitelerinin içmeyenlere göre daha kötü olduğu belirtilmektedir (15). Bu sonuçlardan 
farklı olarak çalışmamızda osteoporotik hastalarda sigara ve alkol kullanımının uyku kalitesini etkilemediği gösterildi.

Düzenli yapılan fiziksel aktivite ile serotonin salgılanmakta, derin dinlenme ve delta uykusunun düzenlenmesi sağlanmaktadır. King ve ark.ları tarafından yapılan bir çalışmada egzersiz aktivitesinin uzun süreli devam ettirilmesinin önemi ortaya konulmuş, 16 hafta süreyle uygulanan orta şiddette egzersizin spor yapmayan sağlıklı erkek ve kadınlarda öznel uyku kalitesini artırdığı ancak bu etkinin ilk 8 haftalık süre içinde ortaya çıkmadığı, daha sonra belirginleştiği vurgulanmıştır (16). Çalışmamızda ise osteoporoz hastalarındaki uyku bozukluğunda fiziksel aktivite düzeyinin önemli olmadığı ortaya konuldu. Tabi bu durumda düzenli fiziksel aktiviteyi daha net ölçen yöntemlerle uyku kalitesindeki etkisinin gösterildiği çalışmalara intiyaç olduğu ortaya çıkmıştır. Bireylerin iyi beslenme alışkanlığıyla uyku kalitesi artmaktadır. Özellikle protein içeren yiyecekler uykuya dalmayı kolaylaştırmaktadır (1). Bununla uyumlu olarak çalışmamızda haftalık süt tüketimi fazla olan osteoporoz hastalarında uyku bozukluğunun daha az olduğunu gözlemledik.

Uyku yoksunluğu olarak günde 6,5 saatten az uyuyan, yeterli uykuya sahip bireyler olarak da günde 6,5-10 saat uyuyan 652'si kadın toplam 1146 kişinin değerlendirildiği bir çalışmada yeterince uyuyamayan kadınların yeterince uyuyan kadınlardan daha düşük kortikal volümetrik KMY değerlerine sahip olduğu bulunmuştur (17). Yani uykusuzluğun kemik yapısında değişikliklere neden olduğu gösterilmiştir. Uykusuzluğun kemik morfolojisinde meydana getirdiği değişikliklerin deneysel olarak da gösterildiği çalışmalar mevcuttur (18). Yetmiş iki gün uyutulmayan sıçanların kontrol grubuna göre dansitometrik ve histomorfometrik incelemeleriyle, kemik tabakasındaki osteoid kalınlığının azaldığı, osteoblast sayı ve aktivitesinin azaldığı öte yandan osteoklastların kontrol grubundan farklı olmadığı gözlenmiştir. Bu çalışmada osteoklast aktivitesinin göstergesi olan plazma TRAP düzeyinin kontrol grubuna göre yüksek olması kemik rezorbsiyonunun da arttığını göstermektedir. Yine femur kemik mineral yoğunluğunun uykusuz olan sıçanlarda kontrol grubuna göre daha düşük olduğu bulunmuştur (18). Yani uykusuzluk hem osteoblast sayısının azalmasına hem de osteoklast fonksiyonlarının artmasına dolayısıyla da KMY'de azalmaya neden olmaktadır. Bununla uyumlu olarak çalışmamızda da uyku bozukluğunun KMY'ye yaptığı olumsuz etkisi gösterilmiştir.

Sogaard AJ ve ark.larının çalışmasında uyku problemlerinin non vertebral fraktürlerle zayıf ilişkisi olduğu gösterilmiştir. Uyku bozukluklarının uzun süreli varlığında ise orta yaşlı kadınlarda tüm osteoporotik fraktür riskleriyle birlikteliğin arttığı belirlenmiştir (19). Çalışmamızda da nonvertebral fraktürlerin uyku bozukluğu olan ve olmayan grupta aynı oranlarda olduğu görülmüştür. Hem uykusuzluk hem de uyku ilacı kullanımı düşmeye eğilim ile birlikte nonvertebral kırık riskinde artışa yol açmaktadır. 8101 kadının alındığı bir çalışmada 5153 kadının kalça kırığı, 1938 kadının da nonvertebral kırık yaşadığı gözlendi (20). Bir yıl içinde iki veya daha fazla düşenlerde gündüz uykululuğunun düşmeyenlere göre belirgin olarak yüksek ve kalça kırıklarının da daha fazla olduğu gösterildi. Özellikle yaşlı kadınlarda düşme ve fraktür riski uykusuzluk ve gündüz uyuklamasıyla artmaktadır. Uykuyu düzelten müdahaleler düşme ve kırık riskini azaltmaktadır (20).

Osteoporozda ağrı en sık rastlanan sorundur. Nedeni ise mikrofraktürler, postür değişikliğinde ortaya çıkan sinir, kas, ligaman zedelenmeleri, mekanik ve kimyasal faktörlerdir ve vücut ağrısı da uykusuzluk için risk faktörüdür (21). Bu durumda çalışmamızda uyku bozukluğu olan osteoporoz hastalarında sırt ağrısını gösteren GAS değerlerinin daha yüksek olması beklenen bir sonuç olarak karşımıza çıkmıştır. Zaten QUALEFFO yaşam kalitesi ölçeğinin ağrı komponentininde uyku bozukluğu olan hastalarda yüksek olması bu ağrıdan dolayı hastaların uykularının bozulmasıyla yaşam kalitelerinin düştüğünü göstermektedir. Cook ve ark. ları çalışmalarında, vertebral kırığının osteoporozlu hastaların \%75'inde kronik ağrıya yol açtığını, emosyonel bir stres kaynağı olduğunu, kişinin işini sürdürmesini, rekreasyonel ve sosyal aktivitelere katılımını ileri derecede kısıtladığını rapor ederek, kırık varlığının yaşam kalitesi üzerindeki yıkıcı etkilerinden söz etmişlerdir (22). Vertebral kırığı olan osteoporotik hastalarda kırı̆ı olmayanlara göre yaşam kalitesinde bozulma birçok kez gösterilmiştir (23-25).

Osteoporotik hastalarda gözlenen uyku bozuklukları bireyin yaşam kalitesini düşürmektedir. Kronik uykusuzluk gündüz uykululuğuna, bilişsel bozulmaya, kaza riskinin artmasına, duygu durum bozukluklarına, yaşam kalitesinin bozulmasına neden olmaktadır. Yaşılırda görülen uyku bozukluklarının bireylerin yaşam kalitelerini olumsuz etkilediği birçok çalışmada gösterilmiştir (26). Çalışmamızda da QUALEFFO yaşam kalitesi ölçeğinin ağ rı, fiziksel işlev, sosyal işlev, genel sağlık algılamasından oluşan tüm alt parametrelerinin ve toplam değerinin uyku bozukluğu olan hastalarda daha yüksek olması, PUKi skorlarının artarken tüm QUALEFFO alt parametre skorlarının da artması bununla uyumludur. Çalışmamızın zayıf noktası ise kontrol grubunun olmamasıdır. Literatürde osteoporozlu hastalarda uyku bozukluklarının ve diğer faktörlerin yaşam kalitelerine etkilerinin araştırıldığı çalışmaların yetersiz olmasından dolayı, vaka sayılarının daha fazla olduğu, randomize kontrollü kurgulanmış yeni araştırmalar gerekmektedir.

Sonuç olarak bu çalışmanın verilerine göre osteoporotik hastalarda yaş, cinsiyet, medeni durum, eğitim seviyesi, diyet gibi faktörlerin uyku kalitesini etkilediğini ve uyku bozukluklarının osteoporotik hastaların yaşam kalitesini olumsuz etkilediğini söyleyebiliriz.

\section{Kaynaklar}

1. Abdulkadiroğlu Z, Bayramoğlu F, ihan N. Uyku ve uyku bozuklukları. Genel Tıp Dergisi 1997;7:161-6.

2. Buysse DJ, Reynolds CF 3rd, Monk TH, Berman SR, Kupfer DJ. The Pittsburgh Sleep Quality Index: a new instrument for psychiatric practice and research. Psychiatry Res 1989;28:193-213.

3. Ağargün YM, Kara H, Anlar Ö. Pitsburg Uyku Kalitesi İndeksi'nin geçerliliği ve güvenirliği. Türk Psikiyatri Dergisi 1996;7:107-11.

4. Lips P, Cooper C, Agnusdei D, Caulin F, Egger P, Johnell O,et al. Quality of life in patients with vertebral fractures: validation of the Quality of Life Questionnaire of the European Foundation for Osteoporosis QUALEFFO. Working party for quality of life of the european foundation for osteoporosis. Osteoporos Int 1999;10:150-60. 
5. Kocyigit H, Gulseren S, Erol A, Hizli N, Memis A. The reliability and validity of the Turkish version of Quality of Life Questionnaire of the European Foundation for Osteoporosis (QUALEFFO). Clin Rheumatol 2003;22:18-23.

6. Http://www.iofbonehealth.org/health-professionals/healtheconomics/quality-of-lifequaleffo41/downloads.html.

7. Vitiello MV. Sleep disorders and aging: understanding the causes. J Gerontol 1997;52:189-91.

8. Atay T. Yaşlılıkta uyku. T Klin Psikiyatri 2001;2:91-7.

9. Chiu HF, Leung T, Lam LC, Wing YK, Chung DW, Li SW, et al. Sleep problems in Chinese elderly in Hong Kong. Sleep 1999;22:717-26.

10. Schechtman KB, Kutner NG, Wallace RB, Buchner DM, Ory MG. Gender, self-reported depressive symptoms, and sleep disturbance among older community-dwelling persons. J Psychosom Res 1997;43:513-27.

11. Karagözoglu S, Çabuk S, Tahta Y, Temel F. Hastanede yatan yetişkin hastaların uykusunu etkileyen bazı faktörler. Toraks Dergisi 2007;8:234-40.

12. Vitiello MV, Larsen LH, Moe KE. Age-related sleep change. Gender and estrogen effects on the subjective-objective sleep quality relationships of healthy, noncomplaining older men and women. J Psychosom Res 2004;56:503-10.

13. Moore PJ, Adler NE, Williams DR, Jackson JS. Socioeconomic status and sealth: The role of sleep psychosom Med 2002;64:337-44.

14. Ohayon MM, Li KK, Guilleminault C. Risk factors for sleep bruxism In the general population Chest 2001;119:53-69.

15. Lexcen FJ, Hicks RA. Does cigarette smoking increase sleep problems? percet. Skills 1993;77:16-8.

16. King AC, Oman RF, Brassington GS, Bliwise DL, Haskell WL. Moderate-intensity exercise and self-rated quality of sleep in older adults. A randomized Controlled Trial. JAMA 1997;277:32-7.

17. Specker BL, Binkley $T$, Vukovich $M$, Beare $T$. Volumetric bone mineral density and bone size in sleep-deprived individuals. Osteoporos Int 2007:18:93-9.
18. Everson CA, Folley AE, Toth JM. Chronically inadequate sleep results in abnormal bone formation and abnormal bone marrow in rats. Exp Biol Med (Maywood) 2012;237:1101-9.

19. Sogaard AJ, Joakimsen RM, Tverdal A, Fonnebo V, Magnus JH, Berntsen GK. Long-term mental distress, bone mineral density and non-vertebral fractures. The Tromso Study. Osteoporos Int 2005;16:887-97.

20. Stone KL, Ewing SK, Lui LY, Ensrud KE, Ancoli-lsrael S, Bauer DC, et al. Self-reported sleep and nap habits and risk of falls and fractures in older women: the study of osteoporotic fractures. J Am Geriatr Soc 2006:54:1177-83.

21. Foley D, Ancoli-Israel S, Britz P, Walsh J. Sleep disturbances and chronic disease in older adults: results of the 2003 National Sleep Foundation Sleep in America Survey. J Psychosom Res 2004; 56:497-502.

22. Cook DJ, Guyatt GH, Adachi JD, Epstein RS, Juniper EF, Austin PA, et al. Development and validation of the mini osteoporosis quality of life questionnnaire (QOLQ) in osteoporotic women with back pain dueto vertebral fractures. Osteoporosis Int 1999;10:207-13.

23. Romagnoli E, Carnevale V, Nofroni I, D'Erasmo E, Paglia F, De Geronimo S, et al. Quality of life in ambulatory postmenopausal women: the impact of reduced bone mineral density and subclinical vertebral fractures. Osteoporos Int 2004;15:975-80.

24. Hall SE, Criddle RA, Comito TL, Prince RL. A case- control study of quality of life and functional impairment in women with long-standing vertebral osteoporotic fracture. Osteoporosis Int 1999;9:508-15.

25. Adachi JD, Loannidis G, Berger C, Joseph L, Papaioannou A, Pickard $L$. The influnce of osteoporotic fractures on health-related quality of life community-dwelling men and women across Canada. Osteoporos Int 2001;12:903-8.

26. Aşkın R, Altan A, Kaya N, Aktitiz Y, Kucur R, Şahin S, et al. Yaşlılarda uyku bozuklukları. Türkiye Tıp Derg 1994;1:47-51. 